\title{
Effect of Sputtered Zinc Oxide as Anti- Reflection Coating in Amorphous Silicon Solar Cell
}

\author{
Dr. Satheesh Babu Gandla ${ }^{1}$, PhD, Nagesh M, M.Tech ${ }^{2}$ \\ Interdisciplinary Research Centre, R. V. College of Engineering, Bangalore, India
}

\begin{abstract}
Amorphous Silicon (a:Si) solar cell structure is modelled and optimized using Lumerical FDTD solution \& Lumerical Device. Sputtered Zinc Oxide (ZnO) transparent layer have been used on these Amorphous silicon solar cells as anti-reflecting coating (ARC). Simulation is done and optical properties and electrical characteristics have been investigated. It is found that the less Reflectance and more transmittance with application of Sputtered ZnO proved that it can be used as AR coatings. It is observed that after using sputtered $\mathrm{ZnO}$ as an ARC, conversion efficiency of solar cell is increased from its original $9.03 \%$ to 11.90 and it is also observed a thickness of 70-90 $\mathrm{nm}$ is optimum for use of the Sputtered $\mathrm{ZnO}$ as anti-reflection coatings.
\end{abstract}

Keywords: Amorphous Silicon (a:Si), Sputtered ZnO, Anti Reflecting Coating(ARC), Conversion Efficiency

\section{Introduction}

The performance of solar photovoltaic cells depends on its design, material properties, and fabrication technology. Numerical simulation is the best approach for solar cell researchers, which help to find out an optimized structure with good fitted parameters. As a result fabrication complexity, costs, and time reduce significantly. The major objectives of numerical modelling and simulation in solar cell research are testing validity of proposed physical structures, geometry on cell performance, and fitting of modelling output to experimental.

Simulation of amorphous silicon solar cells helps in predicting the behaviour of amorphous solar cell devices. As the complexity in design of photovoltaic cells, it becomes more difficult to obtain analytic solutions for their performance. A combination of optical and electrical simulations which account for these non-ideal processes are necessary to accurately characterize the photovoltaic efficiency of the solar cell.

For Optical Simulation FDTD Solutions is used, which is a high performance optical solver that can be used to simulate the interaction of light with a wide variety of solar cell designs. These designs can range from simple planar geometries to very complex patterning, and can include a wide variety of materials such as organics and metals. The result of the optical simulation is the spatial absorption in the substrate region, from which one can calculate the generation rate. This generation rate can be used in an electrical simulation in DEVICE to determine the responsivity and the photovoltaic efficiency of the solar cell. The CHARGE solver in DEVICE will account for the distribution of dopants that give rise to the built-in electric fields, the mobility of free carriers and the physical processes that result in the recombination of charge[11].

The function of solar cell is to obtain light generated carriers and these collection of light generated carriers generate current and power is dissipated in the load,

\section{Methodology}

\section{A.Modelling of a:Si solar Cell}

In this Section, the detail modelling of a:Si solar unit cell is given and defined different material structure which is used and also defined there geometry as shown in Fig.1. Sputtered $\mathrm{ZnO}$ is coated on Glass Substrate which acts Anti Reflecting Coating (ARC). For Simulation in FDTD solution, materials are defined in terms of refractive index and wavelength [12]. It also noted that the thickness of $\mathrm{ZnO}$ of $70 \mathrm{~nm}$ to $90 \mathrm{~nm}$ will be optimum to use it as ARC. The diffusion doping of $\mathrm{N}$ well $(\mathrm{n}++)$ is added with concentration of $1 \times 1019 \mathrm{~cm}-3$ and junction width is $0.4 \mu \mathrm{m}$ and back diffusion $(\mathrm{P}++)$ is added with same concentration of $1 \times 1019 \mathrm{~cm}-3$ and Junction width is $0.2 \mu \mathrm{m}$.

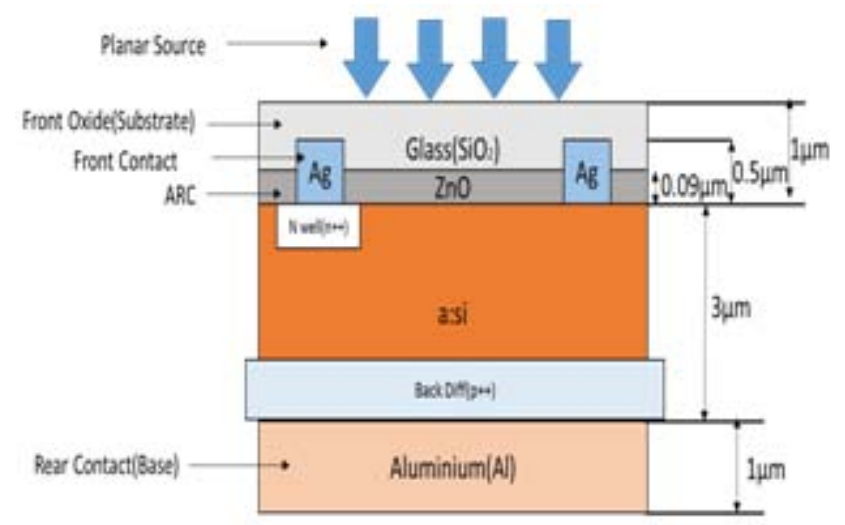

Figure 1: Schematic of a a-Si single-junction solar cell

\section{B. Solar Cell Work flow}

The solar cell workflow starts with optical simulations in FDTD Solutions. Taking the solar spectrum into account, the solar generation rate is calculated from the optical absorption and used as a source in the subsequent electrical simulation in DEVICE to calculate the Conversion efficiency.

\section{Simulation Method}

Using Symmetry of the device, 2D simulation is performed, Using periodic nature of top electrodes, we focused on only one electrical period instead of the whole solar cell, smaller unit cell is chosen in FDTD and by simply repeating this unit 


\section{International Journal of Science and Research (IJSR) \\ ISSN (Online): 2319-7064 \\ Index Copernicus Value (2013): 6.14 | Impact Factor (2014): 5.611}

cell by periods of 18 , the behaviour of whole solar cell can be modelled.

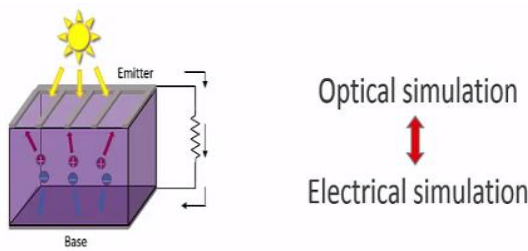

Figure 2: Demonstration of Simulation Methodology

Optical simulation is done using Lumerical FDTD solutions ver 8.12.631. After running simulation, Reflectance of solar cell w.r.t wavelength, Transmittance of solar cell w.r.t wavelength, Solar Generation Rate spectrum and Total optical absorbed w.r.t wavelength are plotted.
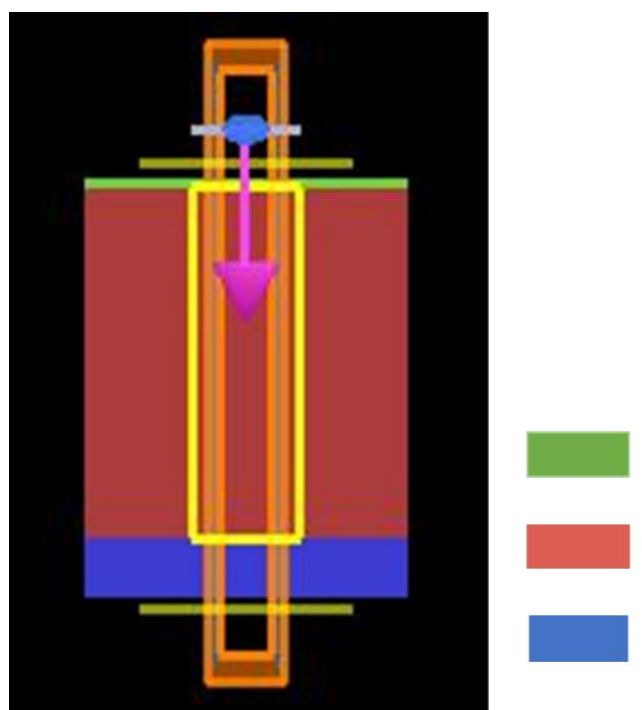

ZnO ARC

$\mathrm{a}: \mathrm{Si}$

Aluminium

Figure 3: View of a: Si unit solar cell in FDTD Analysis

Electrical Simulation is done using Lumerical Device ver 5.0.697 and by Importing Solar Generation Rate as source, obtained electrical characteristics such as P-V Characteristics, short circuit current, open circuit voltage, maximum power obtained, fill factor and solar cell conversion efficiency is calculated for both with and without application of sputtered zinc oxide as Anti reflecting Coating.
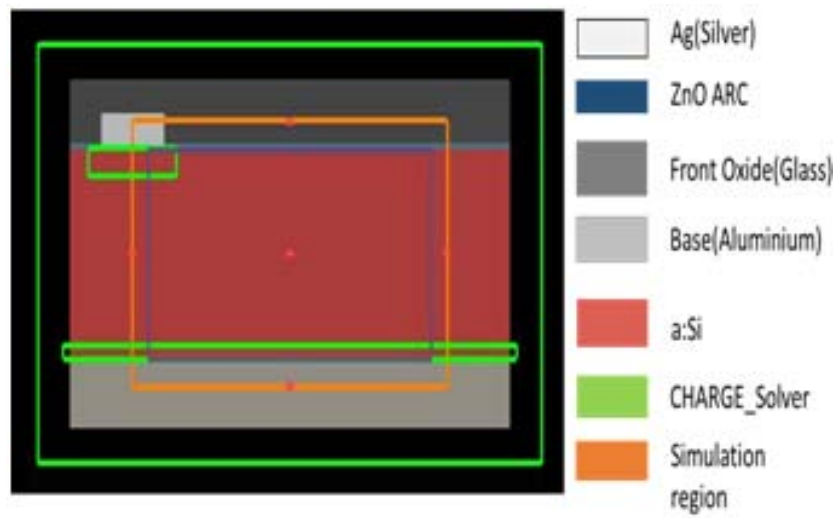

Figure 4: View of a:Si unit solar cell in Device

\section{Results \& Discussions}

Solar cell performance data before and after antireflective coating application for amorphous solar cells is shown from Fig.5 to Fig.9. After application of the sputtered zinc oxide layer the short circuit current density (Jsc) shows a significant increase for in cell due to the AR effect of the coatings. The Voc also increases by a similar amount. The improvement of the short-circuit current density due to the $\mathrm{ZnO}$ AR coatings can be seen and is reflected in the total optical power absorbed plot. Power absorbed curves for amorphous silicon solar cell before and after anti-reflective coating application are shown in Fig 9 (a) and (b), respectively.

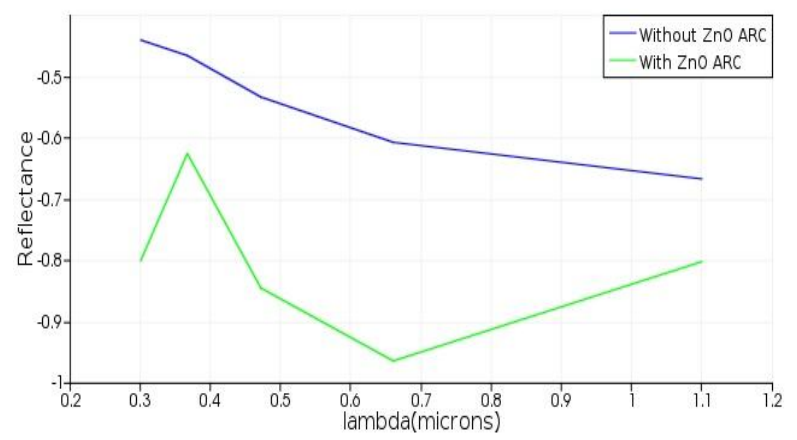

Figure 5: Reflectance of a:Si

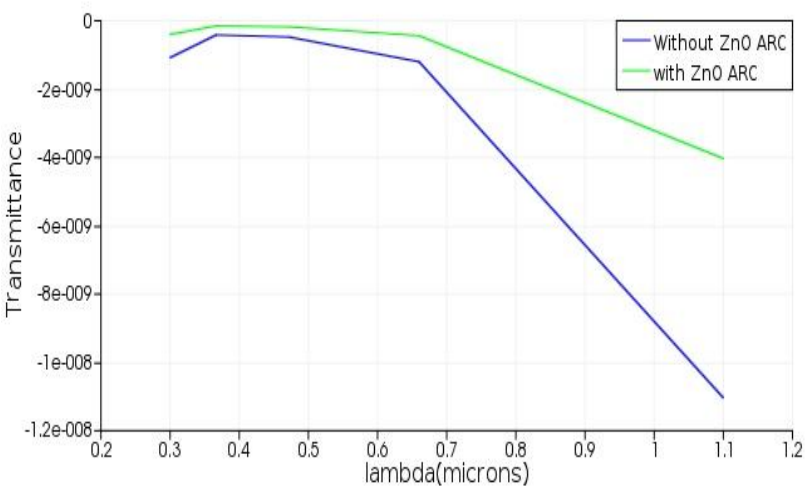

Figure 6: Transmittance of a:Si

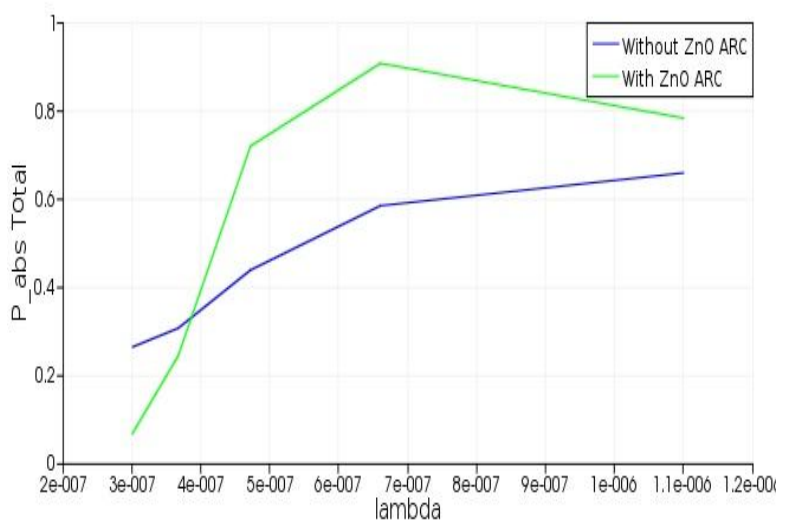

Figure 7: Total Optical Power absorbed by a:Si Unit Cell 


\section{International Journal of Science and Research (IJSR) \\ ISSN (Online): 2319-7064}

Index Copernicus Value (2013): 6.14 | Impact Factor (2014): 5.611

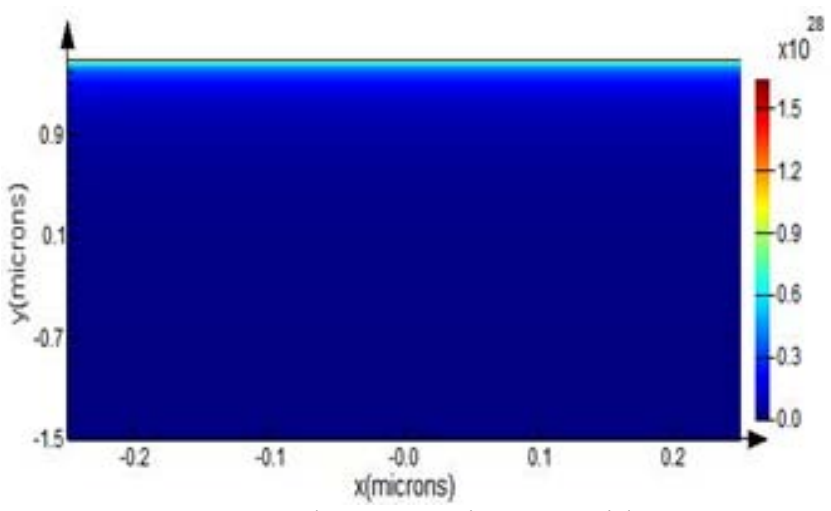

Figure 8(a): Solar Generation rate without AR

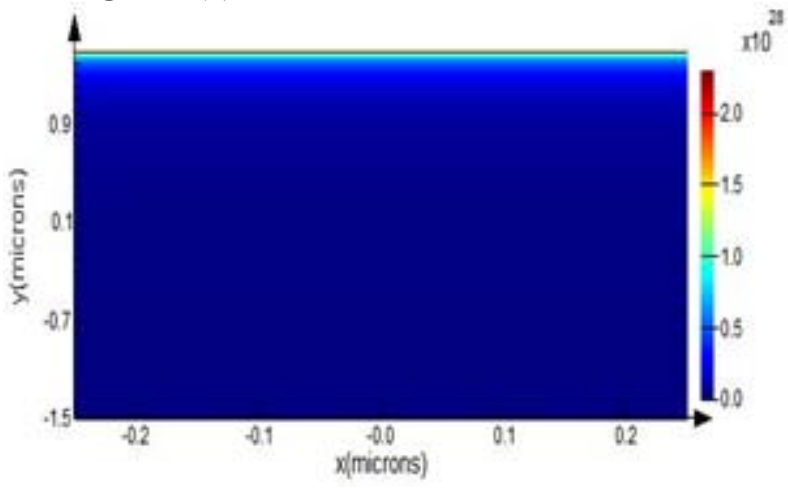

Figure 8(b): Solar Generation rate with AR

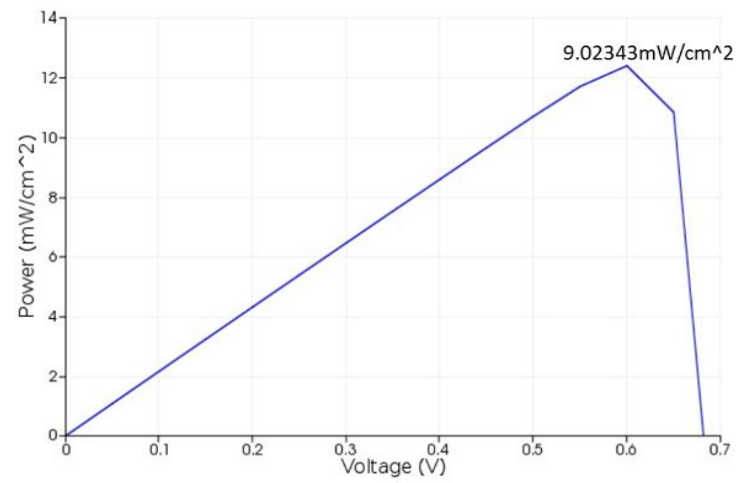

Figure 9(a): $\mathrm{P}-\mathrm{V}$ characteristics without $\mathrm{AR}$

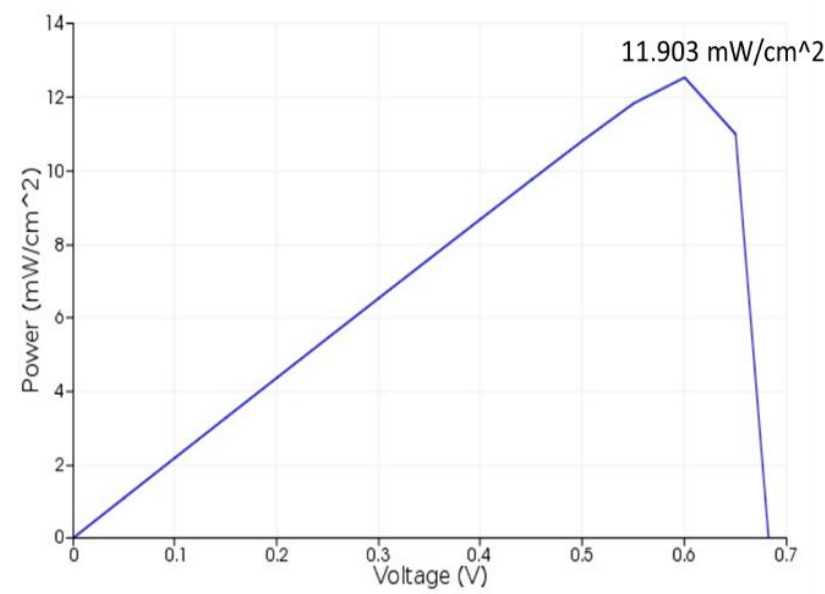

Figure 9(b): P-V characteristics with AR

Table 1: a:Si Solar Cell Parameters

\begin{tabular}{|c|c|c|c|c|c|}
\hline $\begin{array}{c}\text { Parameters/With and } \\
\text { without ARC }\end{array}$ & $\begin{array}{c}\text { Jsc (Ideal) } \\
\mathrm{mA} / \mathrm{cm}^{\wedge} 2\end{array}$ & $\begin{array}{c}\text { Short Curcuit Current(Jsc) } \\
\text { in } \mathrm{mA} / \mathrm{cm}^{\wedge} 2\end{array}$ & $\begin{array}{c}\text { Open Circuit Voltage } \\
\text { ( Voc)In Volts }\end{array}$ & Fill-factor & $\begin{array}{c}\text { Photovoltaic } \\
\text { efficiency }(\mathrm{y})\end{array}$ \\
\hline Without ZnO ARC & 259.372 & 17.7057 & 0.611984 & $83.27 \%$ & $9.02343 \%$ \\
\hline With ZnO ARC & 359.692 & 21.4117 & 0.616237 & $90.2 \%$ & $11.903 \%$ \\
\hline
\end{tabular}

\section{Conclusion}

After investigating the optical and simulation result of a:Si solar cell with and without $\mathrm{ZnO}$, it is found that the less Reflectance and more transmittance with application of Sputtered $\mathrm{ZnO}$ proved that it can be used as AR coatings more efficiently and henceforth making use of the advantages of sputtered Zinc Oxide. The improvement of the short-circuit current density due to the $\mathrm{ZnO}$ AR coatings can be seen and is reflected in the total optical power absorbed plot. It is observed that after using sputtered $\mathrm{ZnO}$ as an ARC, conversion efficiency of solar cell is increased from its original value $9.03 \%$ to $11.90 \%$ and it is also observed a thickness of 70-90 nm is optimum for use of the Sputtered $\mathrm{ZnO}$ as anti-reflection coatings

\section{Comparison with Previous Studies}

The conversion efficiency of $\mathrm{ZnO}: \mathrm{Al}$ as ARC in Crystalline silicon is found to be increased from $10.68 \%$ to $13.10 \%$ [2], so in the same way, the effect of sputtered $\mathrm{ZnO}$ as ARC is conducted on Amorphous silicon solar cell and it is found that conversion efficiency increased from $9.03 \%$ to $11.90 \%$. and also the conversion efficiency of a:Si is found to be on average $9.88 \%$ in previous studies and hence concluding that the optimized design made using Lumerical software is found to be efficient and promising.

Compliance with Ethical Standards

\section{Conflict of Interest}

We authors declare that we have no conflict of interest.

\section{References}

[1] Mohammed Ikbal Kabir, Seyed A. Shahahmadi, Victor Lim, Saleem Zaidi, Kamaruzzaman Sopian, and Nowshad "Amin Amorphous Silicon Single-Junction Thin-Film Solar Cell Exceeding 10\% Efficiency by Design Optimization" International Journal of Photoenergy, 2012.

[2] G.D.K.Mahanama and H.S.Reehal "Effect of Zinc Oxide Antireflective Coatings on Crystalline Silicon Solar Cells" IJETMAS, Vol3, Issue 7, 2015

[3] Bit-Na Go1, Yang Doo Kim, Kyoung suk Oh, Chaehyun Kim, Hak-Jong Choi and Heon Lee1 "Abstract Improved conversion efficiency of amorphous $\mathrm{Si}$ solar cells using a mesoporous $\mathrm{ZnO}$ pattern" Nanoscale Research Letters, 2014 
[4] Yue-Hui Hu, Yi-Chuan Chen, Hai-Jun Xu, Hao Gao, Wei-Hui Jiang, Fei Hu, Yan-Xiang Wang "Texture ZnO Thin-Films and their Application as Front Electrode in Solar Cells"Scientific Research, 2015

[5] Babar Hussain, A.Ebong, Ian Fergueson" Zinc oxide as an active n-layer and anti reflection coating for silicon based heterojunction solar cell" Solar Energy Materials \& Solar Cells, 2015

[6] R. C. Chittick, J. H. Alexander, and H. F. Sterling, "The preparation and properties of amorphous silicon, "Journal of the Electrochemical Society, vol. 116, no. 1, pp. 77-81, 1969.

[7] B. Rech and H. Wagner, "Potential of amorphous silicon for solar cells" Applied Physics A, vol. 69, no. 2, pp. $155-167,1999$

[8] Deckman HW, Wronski CR, Witske H, Yablonovitch E "Optically enhanced amorphous silicon solar cells" Appl Phys Lett 1983,

[9] E. Palik, Handbook of Optical Constants of Solids Vol I, Academic Press, Orlando, pp. 577-580, 1985

[10] O.El Daif, A. Einstein, P.C.P. Bronsveld, R. Ohl, S. Beljakowa, W. Adams, F. Boucher, C. Gueymard, E. Kingsbury, L. McMurdie, et al., "RF-sputtered at $\mathbf{8 0 0}$ W in an Ar atmosphere"Physica Status Solidi, 2015

[11]www.Lumerical.com

[12] www.pvlighthouse.com 